\title{
Ervaringsgeoriënteerde geloofsoordrag: geloofwaardige waarheid
}

\author{
W C Kloppers \\ (Hervormde Teologiese Kollege, UP)
}

\begin{abstract}
Experience-mediated faith - trustworthy truth

The central question in a theological communication theory is the mediation between tradition and experience. How can the reality of God and the reality of human beings be connected on the level of experience? The transmission of the Christian faith is about the mediation of a symbolic reality, meant to bring about spiritual experience and experience of meaning. Not only the cognitive dimension, but the affective, emotive, conative, aesthetic and social dimensions have to play an active role. The communication of faith on all levels of experience is thus a sine qua non for theologians and educators of religion. The challenge for theology is to recognize ways in which experience-driven religious education can be practised.
\end{abstract}

\section{RELIGIEUSE KOMMUNIKASIE - DIE BEMIDDELING TUSSEN DIE GELOOFSTRADISIE EN DIE ERVARING VAN DIE WERKLIKHEID}

"Alle ervaring is kumulatiewe ervaring, met dank aan die voorgeslag"

(Heitink 1993:92)

Die sentrale vraag in ' $\mathrm{n}$ teologiese kommunikasie- of opvoedingsteorie is die vraag na die bemiddeling tussen tradisie en ervaring. Op welke wyse kan die werklikheid van God en die werklikheid van die mens op ervaringsvlak met mekaar verbind word? Wanneer ons besef dat ons binne ' $n$ tradisie is, besef ons terselfdertyd dat ons nie altyd daarin kan wees op dieselfde wyse as wat ons eenmaal daarin was nie (Tracy 1994:138). Beide tradisie en ervaring benodig interpretasie. In die geloofskommunikasie moet ' $\mathrm{n}$ brug geslaan word tussen die geloofstradisie en ons Christen-wees in ' $n$ nuwe situasie. Dit vra om ' $n$ wedersyds kritiese verhouding tussen tradisie en ervaring, waarmee "het sociaal-culturele heden treedt binnen het verstaan en openbaring" (Schillebeeckx 1989:59).

Ons ken God se openbaring indirek, in die vorm van menslike ervaring. Só gesien is die waarheid van God se Woord ' $n$ relasionele waarheid - dit kry in relasie met die mens betekenis. "Wij mensen spreken vanuit onze theologische theorie geen laatste woorden, laat staan eeuwige waarheden. Waarheid is altijd situatief en relationeel bepaald en 
alleen geloofwaardig als zij niet in het verbale blijft steken" (Heitink 1993:151). Ervaring van geloof is onlosmaaklik verbind met die eie werklikheidsverstaan en die eie selfverstaan: "Nur was erfahrbar ist, gilt als glaubhaft, und eine Verkündigung die nicht aus der Erfahrung kommt und nicht zu Erfahrung führt, verhallt schließlich über leeren Kirchenbänken" (Stammler 1974:39).

Die invloed van die werklikheidsverstaan en die houding teenoor die lewe op grond van godsdienstige ervaring, is wedersyds bepalend, daarom moet die teologie poog om aan die religieuse ervaring oor die hele spektrum van die menslike lewe uitdrukking te gee. In die teologie, en veral in die praktiese teologie, word toenemend besef dat daar nie aan die ervaring en waarneming verbygegaan kan word nie. So word ' $\mathrm{n}$ hermeneutiese, ervaringsgerigte teologiebeoefening, godsdienspedagogiek en -didaktiek, liturgiek, pastoraat, en geloofskommunikasie in die breë ook meer prominent.

"Er is duidelik een kloof waarneembaar tussen verstolde religieuze expressie en contemporaire levenservaringen. Nieuwe culturele symbolen en verhalen zijn nodig om deze kloof te overbruggen. Geloof en kerk moeten de huidige cultuur en expressievormen als potentieel religieus gaan zien en cultiveren om met de mensen van vandaag te kunnen communiceren".

(Hoekstra 1991:50)

\section{ERVARINGSGEORIËNTEERDE RELIGIEUSE OPVOEDING}

Ons waarneming van die wêreld word deur ons ervarings gevorm. Ons neem waar wat ons in ons ervaringsordening kan inpas. Ervaring maak dit moontlik om die verlede as die grond vir die toekoms te verstaan. In die ervaring word wat ongestruktureerd is, gestruktureer. In hierdie struktureringsproses word lewens- en toekomsangs verdring. Hierdie dwang om fenomene te orden, veroorsaak egter 'n bepaalde weerstand teen nuwe oriënterings en wegwysings. Eers deur ervarings te omstruktureer kan ons van die dwang daarvan bevry word.

Die vraag waarom vaste ervarings en waarnemingstrukture oop en buigbaar kan word en dus omstruktureer kan word, is ' $n$ elementêre pedagogiese en godsdienspedagogiese vraag. Die christelik-religieuse lewenshouding gaan juis daaroor om bó die gedragswyse van blote aanpassing en ek-bevestiging uit te gaan en om die andersheid van die ander eerder verrykend as bedreigend te ervaar. Godsdienspedagogiese arbeid met jongmense en volwassenes moet dus aan alledaagse ervarings georiënteerd wees. Dit beteken egter nie dat sodanige ervarings die normatiewe maatstaf van die arbeid word nie. Die algemene, "banale" ervaring kan deur godsdienspedagogiese leerimpulse omvorm word, om 
uit die algemene, 'n grondleggende verhouding te vorm, en uit dié weer ' $n$ verhewe ervaring (vgl Barthes 1967:32). Dit kan gebeur wanneer die daarstelling van die alledaagse of die banale as verplasing en bedrog opgeneem word (vgl Zilleßen 1991:74).

Hermeneutiese toegange tot byvoorbeeld ' $\mathrm{n}$ foto lê in ' $\mathrm{n}$ gebied van die nie-vasstelbare, dít wat die presentasievorm foto uitdruklik poog om te verberg. Deur die pedagogiese appèl om noukeuriger te kyk, word ontdekking eerder verhinder. Eers in ' $\mathrm{n}$ vertrouenskeppende en handelingsgeoriënteerde groepatmosfeer kan angs vir die ander, die vreemde, afgebreek word, sodat ander vorme van waarneming van die andere moontlik word. Die praktiese (onderrig)situasie vra om prikkelende impulse wat die verhoudingsgebeure van leraar/onderwyser, leerling en tema in die religieuse onderrigsituasie, kreatief gestalte gee deur wisselende perspektiewe uit te probeer, "fragile, labile und unfertige Sprachund Symbolformen einzuüben, um sich anderen Menschen und der Welt zu nähern, statt sie sich einzuverleiben" (Zilleßen 1991:85). Dit stem ooreen met die breër antropologie-begrip van die postmodernisme wat ook ruimte maak daarvoor dat ervaringsgerigte en leerdergerigte onderrig meer beklemtoon word. Daar word veel meer ruimte geopen vir die rol van die menslike ervaring ten opsigte van alle aspekte van die lewe.

"The role that socialization, culture, ideology, beliefs, power, emotions, dispositions, et cetera, play in the behaviour of people is acknowledged and accounted for in different practices. In the process of learning or understanding, for example, the focus will no longer be solely on the content of what is to be learned, but due consideration will also be given to those subjective experiences that might have an impact on the learner's ability and willingness to acquire that information" (vgl Bruffee 1992:20-22).

Ritter (1985:340) wys daarop dat 'n ervaringsgeoriënteerde daarstelling van die christelike geloof, die outoritêre "bewering", die suiwer rasionele "begronding en bloot empatiese 'Beteuerung" bewustelik vermy. Dit beteken nie dat met hierdie ervaringsgerigte denke en spreke " $n$ waarheidsaanspraak vermy word nie. Dit beteken dat die waarheid nie abstrak "beweer" word nie, maar dat tot eksperimente met die "waarheid" uitgenooi word. Dit beteken dat die huidige teologie telkens weer moet poog om leer(stellings) wat in die laaste instansie tog uit ervaring verkry is en wat ten diepste op nuwe ervaring gerig is, weer vloeibaar te mak. Die grondtaak van die godsdienspedagogiek is om die alledaagse ervaring met behulp van die kreatiewe en inspirerende krag van religieuse en poëtiese taal in elementêre refleksies te rekonstrueer en te vernuwe (Biehl 1991:21). 
Wegenast (1991:37-43) ondersoek ook die moontlikhede van ervaringsgeörienteerde religieuse opvoeding. Hy toon dat die probleme wat hyself vroeër (1987) reeds omskryf het steeds daar is, naamlik ' $\mathrm{n}$ gebrek by Bybeldidakte aan kennis van die kognitiewe bewussyn en die verhouding tot die ontwikkeling van die religieuse en morele oordeel. Kennis van die ontwikkelingpsigologie ontbreek ook. Verder is daar ' $n$ gebrek aan insig in die noodsaak om hul geadresseerdes se biografiese en sosiokulturele voorveronderstellings in ag te neem. Die vraag bly steeds: wat is die brug wat die "Damals" van die tekste en die ervarings daarin, met die teenswoordige lewens- en ervaringswêreld kan verbind? Kan ' $\mathrm{n}$ mens maar net die begrip ervaring besweer, of moet ' $\mathrm{n}$ mens daarheen werk dat steeds meer tussen sosiale, eksistensiële en ander ervarings onderskei word, sodat daardeur die veelvuldige onderskeide op hierdie terrein in berekening gebring word?

Volgens Wegenast (1991) bied die gesprek tussen literatuurwetenskappe, menswetenskappe en teologie wat maar onlangs begin het, nuwe moontlikhede. Hy verwys in die besonder na die resepsie-estetika van Jauß (1981, 1982), Iser (1966) en andere wat met die oog op kinders en jongmense en hul verstaan van Bybelse tekste getoets kan word. Dit kan ook moontlik ander verstaanswyses laat sigbaar word as dié by volwassenes, in wie se verwysingsraamwerk die wetenskaplike eksegese veral probeer dink. Hy wys op Bucher \& Osel (1987), Bucher (1990) as van die eerste in die godsdienspedagogiek wat gepoog het om sodanige vrae te beantwoord, en wat in die godsdienspedagogiek met verwysing na beoefenaars van die resepsie-estetika daarop gewys het dat lees en hoor alles behalwe "ein bloß passiv-rezeptiver Akt ist, sondern als kreative Leistung des Rezipienten angesehen werden muß" (Bucher 1990:9). Die resepsie-estetika gaan van die waarneming uit dat alle lesers, ook wetenskaplikes, dieselfde teks met onderskeie en dikwels teenoorstaande betekenis lees. Dit geld net soveel vir kinders en jeugdiges wat die Bybel lees.

Hier kom die meerdimensionaliteit van tekste ter sprake. Elke teks is meer as wat dit sê - elke aktualisering is noodwendig onvolledig en elke interpretasie is selektief. Nie slegs die teks is "aan die werk" nie, maar bo alles die leser, wat die leë plekke in afhanklikheid aan sy/haar voorverstaan (wat deur sy/haar situasie bepaal is) telkens anders vul. Holub (1984:83 met verwysing na Iser 1966) beskryf die "ideeskeppende aktiwiteit" van die leser wanneer dié onbewustelik " $n$ beeld konstrueer gedurende die leesproses, as passiewe sintese - die "ek" is self as medespeler reeds direk betrokke in die teks. Kinders en volwassenes in die leersituasie moet dus as skeppende en aktief-rekonstruerende subjekte gesien word. 
Die insigte van die ontwikkelingspsigologie, wat die "verstaan" van tekste ook as die gevolg van bepaalde "trappe van ontwikkeling" kan verklaar, moet benut word. Tekste word op verskillende vlakke van ontwikkeling verskillend verstaan en daarom is tekste wat op 'n ander ontwikkelingsvlak lê dikwels onverstaanbaar. Leerders moet die geleentheid gebied word om met leiding na verstaan te soek. Dit kan selfs soms vir die (geloofs)pedagoog nodig wees om die eie verstaan te bevraagteken. In geen geval egter lei die weg na gepaste verstaan, die aktuele Einverständnis met 'n teks, óór 'n enkele dekreet van wat reg sou wees nie. Sodanige dekreet ontmondig net, en ruk die teks (ook in die breër sin verstaan) uit die hand van die kind, maar ook uit die hand van die volwassene en lei ten laaste na ' $n$ "Expertokratie von Exegeten, die ja selbst 'interaktional' gelesen haben. Eine solche Expertokratie ist aber nicht weniger schlimm als Indoktrination, wie wir sie über Jahrhunderte im Rahmen religiöser Erziehung ausgeübt haben" (Wegenast 1991:42).

Bastian (1991:343) sluit by die navorsingsgegewens van die neurofisiologie en neuro-psigologie rakende die funksionering en samewerking van beide breinhelftes aan. Die insigte dat die linker hemisfeer van die brein meer kognitief, analities, talig, rasioneel, bewustelik, klassifiserend, tyd-geörienteerd en sekwensieel dink en die regter hemisfeer meer holisties, intuïtief-onbewus, gelyktydig, ruimtelik-beeld-georienteerd werk en vorme en gestaltes herken, is reeds taamlik algemeen bekend. Volgens die nuwere navorsing is die linkerhelfte eerder op taalfunksies en die regterhelfte op beeldvorming gerig. In die a-verbale regterkant is ook die gevoelens gelokaliseer. Die regterkant is dus nie net sterk ten opsigte van beeldvorming nie, maar ook in die affektiefemosionele kommunikasie. Die suksesvolle samewerking tussen die twee breinhelftes gee "n "Gesamtbewußtsein". Insig in die opbou en werkswyse van die dubbelbrein gee ' $n$ gekwalifiseerde verstaan van die onderskeidelike rolle van waarneming, kommunikasie en nadenke of herinnering.

"Das bildhafte, 'analogische' Denken steht dem Gefühlspol wesentlich näher als das digital-sprachliche; es ist auch informations-reicher und vieldeutiger als dieses. Daraus erklärt sich wahrscheinlich die ungeheure bewußtseinsbildende bzw -befestigende Kraft, die bildhaften Darstellungen bekanntlich seit jeher zukommt. Manche von ihnen, so zum Beispiel die biblischen Vergleiche Jesu, behalten ihre Wirkungen über Jahrtausende. Nicht nur die moderne Reklametechnik, sondern auch die Psychoterapie ... machen sich heute denselben Effekt zunutze" (Springer \& Deutsch 1988:36). 
Bastian (1991:340) toon dat sedert Luther die teologie van die Woord begrond het, die godsdienspedagogiek met veel blokkades gereageer het. Didaktiese metodes is in eenrigtingstrate van sien na hoor, van onderriggesprek na prediking, van die Bybel na die kansel, ingedwing. Die verkondiging van die evangelie word egter al minder gesien as " $n$ "aflaai van godsdienstige informasie" - 'n aangee van (intellektuele) proposisies deur middel van die prediking en outoritêre leersituasies en die rol van sosialisering word veel meer erken: "Waarheid is ...alleen geloofwaardig als zij niet in het verbale blijft steken. Dat betekent, dat wij meer dan ooit zijn aangewezen op intersubjectiviteit binnen werkvormen, waarin mensen, vanuit een gedeeld engagement, in hun handelen werkelijk subject kunnen worden van hun eigen ervaring" (Heitink 1993:151 - my kursivering).

\section{ERVARINGSGEORIËNTEERDE GELOOFSKOMMUNIKA- SIE DEUR DIE EREDIENS}

"Men kan liturgie niet uit een boekje leren, evenmin als feestvieren of hardlopen: nog veel minder kan men liturgie bedenken; men kan haar slechts leren ervaren in een gemeenschap die haar van week tot week of zelfs van dag tot dag praktizeert”.

(Goedhart 1987:126 - my kursivering)

Ervaringsgeoriënteerde geloofskommunikasie vind primêr deur die erediens plaas. Dit is die taak van die gemeente om te verseker dat die volgende geslag deur middel van opvoeding (primêre sosialisasie) en onderwys (sekondêre sosialisasie) ingelei word in die oortuigings, waardes en norme van die gemeenskap en die internalisering daarvan (Van der Ven 1993:122-123). Die erediensbesoek is veral 'n vorm van sosialisering wat die sosiale binding aan die kerklike gemeenskap en dié se simbole beteken. In die erediens speel die tradisie, die oorgelewerde vorme, "n groot rol. In die erediens word die teenwoordiges "taal" en simbole aangegee waardeur hulle gehelp word in hul eie omgang en kommunikasie met God. Die "geloofstaal" kry in die loop van jare vir elke mens persoonlik steeds meer ' $n$ eie uitdrukkingsvorm. In die omgang met rituele is die kognitiewe aanspraak, die verklaring en die leer-verstaan nie die belangrikste nie, maar die sosialisering, met ander woorde die meemaak, die nabootsing, die eenvoudige daarby-wees en die altyd weer daarby-wees. Dit is so dat die die geheimenisse van die geloof en geloofsimbole aangeleer moet word, maar dit kan die praktyk in die omgang met die rituele nie vervang nie - die praktyk gaan trouens die "aanleer" vooraf. Dit het deurslaggewende betekenis vir die godsdienstige sosialisasie van kinders. 
Kinders moet van die begin af in die erediens teenwoordig wees en daarin opgroei. Die kindervriendelike erediens is dus nie iets willekeurig en sekondêr nie, maar die erediens waarin kinders ruimte het, is 'n elementêre noodwendigheid vir die bemiddeling van die Christelike geloof. Daiber (1992:18) spreek die vermoede uit dat die "kinderfreie" eredienste waar kinders glad nie die erediens bywoon nie of apart besig gehou word, baie skadelik vir die oorlewering van die geloof is. Die ouers se rol en voorbeeld is deurslaggewend vir die sosialiseringsproses - hul "Mitgehen", hul "Dabeisein", hul deelname, is bepalend. Kinders moet geleidelik die estetiese van die kerkgebou, die musiek en ander aspekte leer waarneem en daarvan begin sin maak. Dit gaan dus nie net om die verbaal-kognitiewe verstaan nie, maar daarom dat elke aspek van die liturgie as omvattende "Gesamtkunstwerk" van beelde, rituele, rites, musiek, verhale, tekste en metafore deur alle ouderdomsgroepe ervaar moet word (vgl Kloppers 1997:114-117).

\section{SAMEVATTING}

In die oordra van die geloof gaan dit om die kommunikering van ' $\mathrm{n}$ simboliese werklikheid, gerig op spirituele belewing en singewing, waarin nie alleen die kognitiewe dimensie, maar ook die affektiewe, sosiale, emotiewe, konatiewe en estetiese dimensie ' $n$ rol speel. Die invloed van die onderbewuste en onbewuste op die bewuste denke, die pre-konseptuele en die nie-konseptuele op die konseptuele en die irrasionele op die rasionele, moet ook verreken word. In die teologie moet die omgang met die religieuse oorlewering én die ervaring van die werklikheid ter sprake kom. Ervaringsgerigte geloofskommunikasie is dus ' $n$ sine qua non vir alle teoloë, geloofspedagoë en godsdiensdidakte. Die wetenskaplike omgang met die werklikheid moet altyd ' $n$ stuk verder teruggeneem word: "Es gibt Dinge, die durch Analyse, Reflexion und Theorie, nicht zureichend erfaßt werden können, die sich der Vergegenständlichung entziehen" (Cornehl 1991:303). Daarom moet die nieobjektiverende omgang met die werklikheid van die godsdiens ook ' $\mathrm{n}$ plek kry in alle teologiese vorming en opleiding. Die groot uitdaging vir elke aspek van teologiebeoefening en godsdiensuitlewing is om voortdurend nuwe wyses van ervaringsgeörienteerde geloofskommunikasie en geloofsoordrag te bedink.

Waarheid is ... alleen geloofwaardig als zij niet in het verbale blijft steken...

\section{Literatuurverwysings}

Barthes, R 1967. Kritik und Wahrheit. Frankfurt: Suhrkamp.

Bastian, H 1991. Auge und Ohr, Sehen und Hören: Eine Revision theologischer Mediendidaktik, in Zilleßen et al 1991, 339-352. 
Biehl, P 1991. Symbole geben zu verstehen. Zur praktische-theologischen Bedeutung der Symbolhermeneutik Paul Ricoeurs, in Zilleßen et al 1991, 141-160.

Bruffee, K A 1992. Science in a postmodern world. Change Sept/Okt 1992, 18-25.

Bucher, A \& Oser, F 1987. "Wenn zwei das gleiche Gleichnis hören...”. ZfPäd 33, 167183.

Bucher, A 1990. Gleichnisse verstehen lernen. Fribourg: Universitäts Verlag (Praktische Theologie im Dialog 5).

Cornehl, 1991. Lieder - Lyrik - Liturgien. Sprache des Glaubens - Sprache des Zweifels, in Zilleßen et al 1991, 297-306.

Daiber, K-F 1992. Gottesdienst unter den Bedingungen der gegenwärtigen Gesellschaft. Für den Gottesdienst 39/40, 9-20.

Goedhart, T 1987. Nieuwe muziek in de liturgie: een reactie. Het Orgel 83(4), 126-129.

Hahn, J G \& Hoekstra, H (samenst.) 1991. Een gesprek over film en televisie: over de theorie en de praktijk van "het mediagesprek", Kampen: Kok.

Hoekstra, H 1991. Audiovisuele media en het mediagesprek: hun zin en betekenis voor geloofsbeleving en kerkgemeenschap, in Hahn \& Hoekstra 1991, 43-65.

Heitink, G 1993. Praktische Theologie: geschiedenis, theorie, handelingsvelden. Kampen: Kok.

Holub, R C 1984. Reception theory: A critical introduction. New York: Mcthuen.

Iser, W 1966. Immanente Ästhetik. München: Kaiser.

Jauß, H R 1981. Zur Abgrenzung und Bestimmung einer literarischen Hermeneutik, in Frank, M, Jauß H R \& Pannenberg W (Hrsg) 1981. Poetik und Hermeneutik IX, Text und Applikation, 459-481. München: Kaiser.

Jauß, H R 1982. Ästhetische Erfahrung und literarische Hermeneutik. Frankfurt: Suhrkamp.

Kloppers W C 1997. Die kommunikatiewe vermoë van die parateks van kerkpublikasies. DTh-proefskrif: Universiteit van Suid-Afrika.

Ritter, W 1985. Erfahrung. Plädoyer für einen anderen 'Stil' theologischen Denkens und redens. $\operatorname{ThPr} 20 / 4,339-49$.

Schillebeeckx, E 1989. Mensen als verhaal van God. Baarn: Ambo.

Springer, S \& Deutsch, G 1988. Linkes-rechtes Gehirn. Funktionelle Asymmetrien, 2. Aufl. Heidelberg: Kerle.

Stammler, E 1974. Kirche am Ende unseres Jahrhunderts. Stuttgart: Kreuz.

Tracy, D 1994. On naming the present: Reflections on God, hermeneutics, and the church. Mary Knoll, NY: Orbis Books.

Van der Ven, J 1993. Ecclesiologie in context. Kampen: Kok.

Wegenast, K 1983. Bibel - ganz anders, in Heimbrock, H, Spiel-Räume. Kreativität im Horizont des christlichen Glaubens. Neukirchen: Vluyn.

-, 1987. Bibeldidaktik 1975-1985. JRP 3, 127-152.

Wegenast, K 1991. Hermeneutik und Didaktik, in Zilleßen et al 1991, 23-43. 
Zilleßen, D (Hg) 1991. Praktisch-theologische Hermeneutik, Ansätze - Anregungen Aufgaben. Rheinbach-Merzbach: CMZ Verlag.

Zilleßen, D 1991. Religionspädagogische Lernwege der Wahrnehmung, in Zilleßen et al 1991, 59-85. 